\title{
Medical Error became Sword for Innocent Eyes: On Shadow of Negligence
}

\author{
Santosh Kumar ${ }^{*}$ and Shumaila Batool
}

School of Nursing and Midwifery, Aga Khan University, Karachi, Pakistan

*Corresponding author: Santosh Kumar, School of Nursing and Midwifery, Aga Khan University, Karachi, Pakistan, Tel: +92 3333267825; E-mail: santosh.kumar.mn15@student.aku.edu

Received date: August 08, 2016; Accepted date: August 29, 2016; Published date: August 31, 2016

Copyright: $\odot 2016$ Kumar S, et al. This is an open-access article distributed under the terms of the Creative Commons Attribution License, which permits unrestricted use, distribution, and reproduction in any medium, provided the original author and source are credited.

\begin{abstract}
Medical error is serious health problem among the healthcare organizations but major drawback is that errors are not disclosed, and remains hidden. It is necessary to maintain the standards of practice, information and error to be disclosed to reasonable person and if it is not so it is against the professional practice, and authority have to feel physician guilty for negligent disclosure. This commentary article is a scholarly examination of the ethical issue confronted in the health care setting, based on the case study of little girl who lost her life due to medical error but the parents were not informed about it and everyone did negligence, and case was not reported to higher authorities.
\end{abstract}

Keywords: Medical error; Negligence; Disclosure; Health professionals

\section{Scenario}

A seven year old girl presented to emergency department (ED) with insect bite. She received a full evaluation in ED, and child was continuously crying along with treatment [1]. Consultant ordered resident to administer injection Diazepam. Resident directly administers $3 \mathrm{cc}$ through intravenous route and this amount is high enough to cause adverse effects. The child condition was getting worse, when it was clear that child could not survive consultant met with parents, and informed that insect is poisonous and there is very low chance that child will survive and final child had respiratory arrest and died. Consultant had instructed all healthcare professionals (HCP) at ED not to disclose this error and not to comment on care. The incident was not reported, and information was not conveyed to the higher authorities.

\section{Introduction}

Medical error is a failure of treatment which leads or potential to lead to harm the patients [2]. Negligence is doing of the act which prudent person is not legally responsible to do as by law. Before reflecting upon this case let's start by posing relevant questions, "Is every health care professional (HCP) not liable to disclose the error?" and "Is the consultant took right step?" if so how could the fairness and truthfulness be justified? At a one side the resident did error on the other consultant did negligence by telling lie to parents of child. Some authors asserted that medical error is serious health problem among the healthcare organizations but major drawback is that these errors are not disclosed remains hidden. Though, the code of ethics of practice for professionals clearly states that the patient and family have a right to know about medication, its risk and benefits, and errors [3]. Health professional have a responsibility to convey the information but these guidelines are not followed in a practice. However, medical error is a fact that cannot be denied but can be minimized and the negligent disclosure encounters a lot. This paper is based on a clinical scenario of little girl died at hospital as a result of medical error and lack of practice of professional.

\section{My Position}

In clinical setting, HCP's follows ethical principles, values patient's moral beliefs, and performs practices with sincerity closed to it several unethical, illegal acts, and errors became a part of health care system. After internalizing the picture, in my view point the case of girl child is a one example there are many much more cases that how HCP's are hiding the error, and doing negligence. To maintain the standards of practice, information and error to be disclosed to reasonable person and if it is not so it is against the professional practice, and authority have to feel physician guilty for negligent disclosure [4]. The code of ethics justifies that disclosure of error preserve the trust and HCP's should avoid negligence and to be honest in the litigation and law of medical settings. The code of ethics, and practitioner guidelines clearly states that health professional strive to expose the physician deficient and competence or who engage in deception, and practitioner always adopts good, accurate and rational practice in both prescribing and administrating drugs [5]. However, these guidelines are available but they are not followed and this incident highlights the lack of practices of the guidelines. According to the history of medical ethics, the physician is obligated to disclose the information, liable for fairness, and perform the duty of care in order to live up the standards of quality practices. However, disclosing error is a difficult task but concealing information, contributes in increasing the malpractice and negligence and immediate revelation of complex facts may postpone until more suitable time [6]. These findings support my stance that professional organize appropriate settings for the conversation for disclosure of error and negligence to be avoided, and authority decides as per to law, policies, and one to be feel guilty in negligent disclosure.

\section{Counter Arguments}

On the other hand, consultant was also right as the incidence was done unintentionally as a result of medical error and immediate disclosure may results in fatal effects. Concealing error and negligence may be due to fear of punishment, malpractice lawsuit, negligent 
Page 2 of 2

homicide, and harm to residents and hospital [7]. Many organizations coerce HCP's to hide the information in order to maintain both professional and hospital reputation so may be it is due to organizational pressure. It is fact that when complicated mistakes occurs the liability for negligence may arise. Hiding error and negligence was also the reasonable as immediate revelation is like pushing a resident in danger and being a team HCP's are responsible to respect, value, guide, and help coworkers in problematic situations.

\section{Justification of My Position}

I consider that my stand is ethical sound because ultimately this picture maintains stability between health system, professionalism, and intentions were to do good (beneficence) for human beings. Though, medical error is human to persevere it is diabolical and intentions of decisions should crops good to patients and to others. Disclosing error is ethical but it is to be on appropriate time in order to avoid violence and preserve the humanity, ethics, and laws. Disclosing error, avoiding negligence, feeling guilty for act and sympathy improves trust, do fairness, and shows truthfulness. Subsequently, it is in the benefits of medical science, humanity and maintenance of quality and standard of care.

\section{Possible Consequences}

My standpoint is powerfully in the favor of disclosing the error at right period, disciplining the negligent disclosure, and justification with patients, professionals, and practices according to policies, laws and code of ethics. Some of the benefits of concealing the information are in a favor of saving co-workers, avoiding from guilt, and maintaining professional and hospital reputation. However disclosure and negligence may leads to penalties, harm, loss of trust, and malpractice lawsuit.

\section{Recommendation}

The implication of my position for HCP's is clear. It's necessary that errors to be revealed, documented and hospital management not to support neglect disclosures and actions to be taken as per institutional policies. The HCP's to be instructed to follow the code of ethics and highlight such ethical issues and report to authorities for maintaining the truthfulness, and fairness in health care system. Hiding the information and negligence is always perceived in a negative light regardless of intentions and consequence. The responsible person should promptly subject a statement accepting responsibility into part in the mistake. However, the code of ethics and guidelines for practices are available but they were not followed in practice, therefore the proper policies to be developed, implemented, and session to be arranged so everyone is liable to act and follow the guidelines. Moreover, the higher authorities should introduce continues monitoring system in hospitals to check the performance, and practice of health professional in order to overcome with these types of incidences.

\section{Conclusion}

The HCP's perceives that concealing the error is a safe method to avoid from consequence; however, in reality the safer method is to disclose the information, avoid negligence and follows code of ethics. In such situations, it is difficult for HCP's to take decisions and maintain balance between professionalism, practice and patients family rights. So as a human being one should not feel comfort in organizational silences. All ethical aspects have their own specific worth associated to specific situations. However, the major theme is to live for humanity, serve humanity, show compassion and will to help patients.

\section{References}

1. Beauchamp TL, Childress JF (2001) Principles of Biomedical Ethics. Oxford University Press, USA.

2. Aronson JK (2009) Medication errors: definitions and classification. Br J Clin Pharmacol 67: 599-604.

3. (2011) Pakistan Medical and Dental Council Guidelines, Pakistan.

4. Burkhardt M, Nathaniel A (2013) Ethics and Issues in Contemporary Nursing. Cengage Learning.

5. Selbst SM (2003) The difficult duty of disclosing medical errors. Contemp Pediatr 20: 51-63. 